\title{
RANCANG BANGUN SISTEM INFORMASI GEOGRAFIS PEMETAAN OPTICAL DISTRIBUTION POINT (ODP) PADA PT. TELKOM AKSES BALI SELATAN BERBASIS WEB DAN ANDROID
}

\author{
Anak Agung Dewi Sintyarianti ${ }^{1}$, I Made Arsa Suyadnya ${ }^{2}$, Duman Care Khrisne ${ }^{3}$ \\ Jurusan Teknik Elektro, Fakultas Teknik, Universitas Udayana \\ Email: dewisintyarianti@gmail.com ${ }^{1}$, arsa.suyadnya@unud.ac.id ${ }^{2}$, duman@unud.ac.id ${ }^{3}$
}

\begin{abstract}
ABSTRAK
PT Telkom Akses (PTTA) adalah perusahaan penyedia layanan konstruksi dan pengelolaan infrastruktur jaringan. Perusahaan ini mengalami berbagai kendala dalam mengelola insfrastruktur jaringan. Salah satunya adalah tidak efisien-nya koordinasi antara teknisi dan helpdesk saat melakukan penyambungan ODP. Agar teknisi dapat segera menyambungkan pelanggan dengan ODP terdekat, maka para teknisi membutuhkan informasi lokasi spesifik dari ODP yang ingin diperbaiki. Selama ini tidak ada sistem pemetaan ODP yang digunakan. Berdasarkan permasalahan yang ada, maka pada penelitian ini mengusulkan perancangan dan pembangunan aplikasi Sistem Informasi Geografis pemetaan ODP bebasis web untuk helpdesk dan berbasis aplikasi mobile Android untuk teknisi. Berdasarkan hasil pengujian aplikasi dengan metode Blackbox testing, seluruh fungsionalitas dari sistem pemetaan ODP web dan Android yang telah dibangun dapat berjalan dengan baik.
\end{abstract}

Kata Kunci : Sistem Informasi Geografis, Optical Distribution Point (ODP), mobile, Black-box testing

\begin{abstract}
PT Telkom Access (PTTA) is a provider of network infrastructure construction and management services. The company is experiencing various obstacles in managing network infrastructure. One of them is the inefficient coordination between technicians and helpdesk when connecting ODP. In order for technicians to immediately connect customers with the nearest ODP, the technicians need specific ODP location information to be fixed. So far no ODP mapping system has been used. Based on the existing problems, then this research proposes the design and development of Geographic Information System Application mapping ODP web-based for helpdesk and Android mobile-based apps for technicians. Based on the results of testing the application with Black-box testing method, all the functionality of ODP mapping system on web and Android that has been built can run well.
\end{abstract}

Keywords: Geographic Information System, Optical Distribution Point (ODP), mobile, Black-box testing.

\section{PENDAHULUAN}

PT. Telkom Access, merupakan anak perusahaan PT. Telekomunikasi Indonesia Tbk. terlibat dalam pembangunan infrastruktur jaringan dan managed service. PT. Telkom Akses didirikan pada tanggal 12 Desember 2012. Komponen penting yang ada pada jaringan berbasis serat optik adalah Optical Distribution Point (ODP).

Sesuai dengan data dari PT Telkom Akses, terdapat 14.650 buah ODP yang tersebar di wilayah Bali Selatan. Jumlah teknisi yang ada berjumlah 120 orang yang dibagi kedalam 11 wilayah operasi [1]. Salah satu masalah yang dihadapi adalah tidak efisiennya koordinasi antara teknisi dengan helpdesk saat melakukan penyambungan pada ODP.
Jumlah pelanggan yang banyak dan tersebar di berbagai lokasi menyebabkan koordinasi memakan waktu yang lama. Agar teknisi dapat segera menyambungkan pelanggan dengan ODP terdekat, maka para teknisi membutuhkan informasi lokasi spesifik dari ODP yang ingin diperbaiki.

Sisem Informasi Geografis (SIG) dapat mengatasi masalah pengelolaan ODP yang tersebar di berbagai wilayah. Sistem informasi geografis (SIG) memungkinkan kita memvisualisasikan, mempertanyakan, menganalisis, dan menginterpretasikan data untuk memahami hubungan, pola, dan tren.. Sistem Informasi Geografis menyajikan data atau informasi menggunakan peta dalam 
bentuk grafis sebagai antarmuka. Di dalam upaya menangani informasi-informasi spasial atau yang bereferensi geografi, sejak 1970-an telah dikembangkan suatu SIG otomatis. Salah satu contoh penggunaan SIG yaitu untuk pemetaan, diantaranya penelitian Pemetaan BTS di Sumbar pada PT Axiata [2] dan pemetaan Pemancar GSM di Makassar [3]. Penelitian tersebut mengintegrasikan data setiap Base Transceiver Station (BTS) sehingga mempercepat akses pengguna terhadap lokasi, jumlah dan biaya operasionalnya.

Berdasarkan permasalahan yang ada, maka pada penelitian ini penulis mengusulkan perancangan dan pembangunan Sistem Informasi Geografis pemetaan ODP pada PT Telkom Akses wilayah Bali Selatan bebasis web pada sisi helpdesk dan berbasis mobile pada sisi teknisi.

\section{KAJIAN PUSTAKA}

\subsection{Optical Distribution Point (ODP)}

Optical Distribution Point digunakan di Bangunan atau Luar. Kabel utama melalui ODP terhubung ke kabel Drop yang disediakan oleh splitter [2]. Keunggulan dari ODP yaitu solusi perawatan yang mudah untuk instalasi luar dan pemasangan di dinding, menyediakan ruang kerja maksimum dan tekuk ketentuan radius untuk semua kabel dan konektor pasif, ODP juga merupakan perangkat penghubung kabel cross device yang biasanya dipasang pada tiang telepon. Alat yang digunakan dalam sistem multiplexing dan routing saluran yang berbeda seperti cahaya yang masuk atau keluar dari single mode fiber (SMF). Kabel ini merupakan jenis kabel optik yang umumnya digunakan untuk pembangunan jaringan telekomunikasi. Untuk contoh ODP dapat dilihat pada Gambar 1.

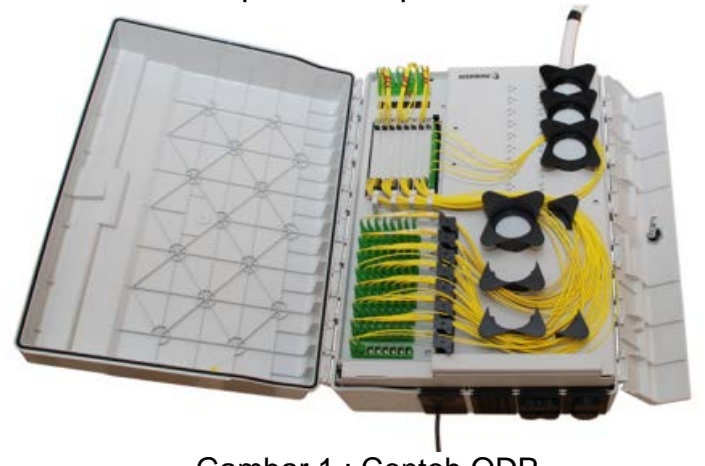

Gambar 1 : Contoh ODP

\subsection{Sistem Informasi Geografis}

Sistem informasi geografis (SIG) memungkinkan kita memvisualisasikan, mempertanyakan, menganalisis, dan menginterpretasikan data untuk memahami hubungan, pola, dan tren. GIS menguntungkan organisasi dari semua ukuran dan hampir di setiap industri. Ada ketertarikan dan kesadaran akan nilai ekonomi dan strategis GIS. [5].

GIS adalah teknologi go-to untuk membuat keputusan yang lebih baik mengenai lokasi. Contoh umum meliputi pemilihan lokasi real estat, pemilihan rute / koridor, perencanaan evakuasi, konservasi, ekstraksi sumber daya alam, dan lain-lain. Membuat keputusan yang benar tentang lokasi sangat penting bagi keberhasilan sebuah organisasi. Sistem Informasi Geografis benar-benar berawal dari 4 gagasan sederhana:

- Buat data geografis

- Mengelolanya

- Menganalisis

- Tampilkan di peta.

\subsection{Model Proses Waterfall}

Model proses waterfall merupakan model proses untuk pengembangan perangkat lunak yang pelaksanaan proses pengembangannya ini dilakukan secara berurutan. Pengertiannya aktivitas pengembangan berikutnya baru dapat dimulai jika aktivitas sebelumnya sudah diselesaikan terlebih dahulu. [6]. Gambar 2 merupakan tahapan model proses Waterfall.

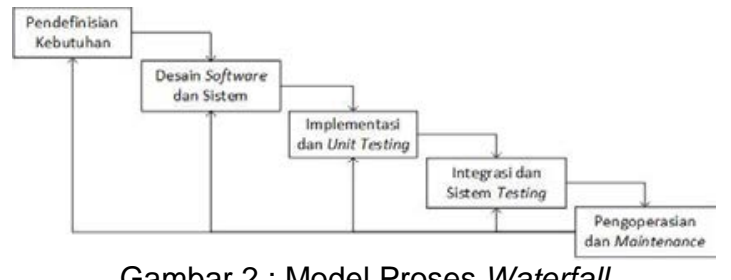

Gambar 2 : Model Proses Waterfall

Setiap tahapan aktivitas pada model proses waterfall ini akan menghasilkan keluaran yang diperlukan sebagai bahan masukan untuk melanjutkan ke tahap berikutnya, atau sebagai umpan balik untuk memperbaiki kekurangan atau kesalahan yang mungkin ada di tahap sebelumnya.

\subsection{Web Service}

Web Service adalah bagian dari perangkat lunak yang membuat dirinya tersedia melalui internet dan menggunakan sistem pesan XML standar. XML digunakan untuk mengkodekan semua komunikasi ke layanan web. Misalnya, klien memanggil layanan web dengan 
mengirim pesan $\mathrm{XML}$, kemudian menunggu tanggapan XML yang sesuai. Karena semua komunikasi ada dalam XML, layanan web tidak terkait dengan sistem operasi atau bahasa pemrograman apa pun - Java dapat berbicara dengan Perl; Aplikasi Windows bisa berbicara dengan aplikasi Unix. [7]

Web Service merupakan sistem pertukaran informasi berbasis XML yang menggunakan Internet untuk interaksi aplikasike-aplikasi langsung. Sistem ini dapat mencakup program, objek, pesan, atau dokumen. Platform dasar web service adalah $\mathrm{XML}+\mathrm{HTTP}$. Semua layanan web standar bekerja dengan menggunakan komponen berikut :

- SOAP (Simple Object Access Protocol)

- UDDI (Universal Description, Discovery and Integration)

- WSDL (Web Services Description Language)

\subsection{Android}

Android adalah sistem yang cukup kompleks. Bagian dari sistem Android yang mengeksekusi kode DEX yang dikompilasi disebut Dalvik Virtual Machine (DVM). DVM itu sendiri adalah perangkat lunak yang ditulis dalam bahasa lain yang berjalan pada versi sistem operasi Linux yang disesuaikan secara khusus [4].

API Android adalah sebagian besar kode Java. Ini kemudian dikompilasi menjadi kode DEX dan dijalankan oleh DVM, yang pada gilirannya memiliki koneksi ke sistem operasi yang mendasari yang disebut Linux. Kemudian produsen perangkat Android dan komponen perangkat keras individu menulis perangkat lunak canggih yang disebut driver, yang memastikan bahwa perangkat keras mereka (CPU, GPU, penerima GPS, dan sebagainya) dapat berjalan di sistem operasi Linux yang mendasarinya.

\subsection{Google Maps API}

Google maps API adalah fungsi fungsi pemrograman yang disediakan oleh Google maps agar Google maps bisa di integrasikan kedalam Web atau aplikasi yang sedang buat [8]. Google Maps yang dapat ditemukan di alamat http://maps.google.com. Google Maps API menyediakan beberapa fitur untuk memanipulasi peta, dan menambah konten melalui berbagai jenis services yang dimiliki, serta mengijinkan kepada pengguna untuk membangun aplikasi enterprise. API secara sederhana bisa diartikan sebagai kode program yang merupakan antarmuka atau penghubung antara aplikasi atau web yang kita buat dengan fungsi-fungsi yang dikerjakan.

\section{METODE PENELITIAN}

Dalam pembuatan sistem informasi pencarian Optical Distribution Point (ODP) ini penulis mengambil lokasi di Kantor PT Telkom Akses Wilayah Bali Selatan. Dalam penelitian ini, jenis data yang digunakan dibedakan menjadi dua jenis, yaitu data primer dan data sekunder.

\subsection{Tahapan Penelitian}

Tahapan penelitian yang dilakukan mengikuti siklus hidup pengembangan software waterfall yang terdiri dari :

1. Analisis kebutuhan:

Pada tahap ini kegiatan yang dilakukan adalah: Mengidentifikasi kebutuhan pemakai sistem informasi geografis pemetaan ODP dan mengidentifikasi kebutuhan fungsional sistem informasi geografis pemetaan ODP

2. Perancangan sistem :

Perancangan prosedur atau konsep eksekusi sistem yang dimodelkan menggunakan Unified Modeling Language (UML). Perancangan database yang dimodelkan menggunakan Entity Relationship Diagram (ERD). Perancangan antarmuka dari komponenkomponen sistem.

3. Implementasi sistem

Sistem dari sisi helpdesk akan dibangun menggunakan bahasa pemrograman PHP, Apache Web Server, Database MySQL, dan aplikasi pendukung lainnya. Sistem dari sisi pengguna dibangun menggunakan bahasa pemrograman Java, Java Development Kit (JDK), SDK Android, IDE Android Studio.

4. Pengujian sistem

Pengujian yang dilakukan pada penelitian ini bertujuan untuk mengetahui apakan sistem yang dibangun sudah sesuai dengan kebutuhan pengguna. Jenis pengujian yang dilakukan adalah pengujian kebutuhan fungsional sistem dengan teknik black-box [4].

\subsection{Gambaran Umum Sistem}

Sistem informasi geografis pemetaan ODP yang akan dibangun pada penelitian ini 
memiliki empat komponen yaitu; Database, Web Service, Sistem sisi teknisi, Web Server dan sistem sisi helpdesk. Hubungan antar komponen tersebut dapat dilihat pada Gambar 3.

Sistem sisi teknisi yang berbasis mobile akan berkomunikasi dengan web service untuk memperoleh data lokasi ODP dan data ODP yang dibutuhkan. Dalam memberikan layanan, web service tersambung dengan database sebagai penyedia data. Sistem sisi helpdesk akan langsung berkomunikasi dengan web server untuk membaca maupun menyimpan data pengguna dan data ODP. Data lokasi yang ada pada sistem mobile maupun web berbentuk latitude dan longitude. Data latitude dan longitude akan dikirimkan ke Google Maps API untuk memperoleh lokasi suatu objek dalam peta.

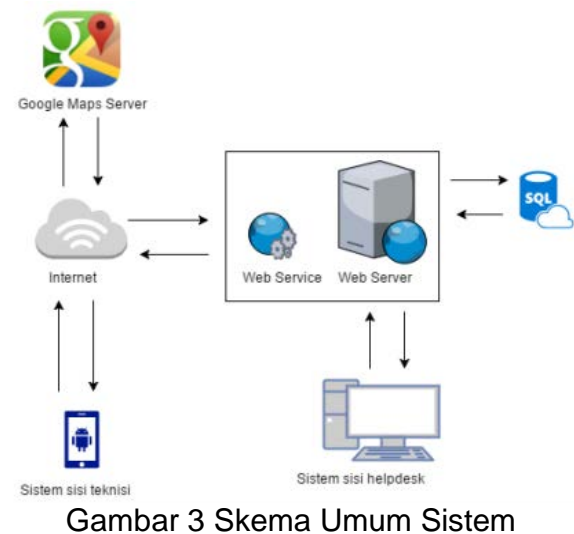

\subsection{Perancangan Sistem}

Perancangan sistem diGambarkan dengan menggunakan Usecase Diagram. Pada sistem informasi geografis pemetaan ODP terdapat dua UseCase yang dirancang, yaitu UseCase system untuk sisi helpdesk dan sisi teknisi.

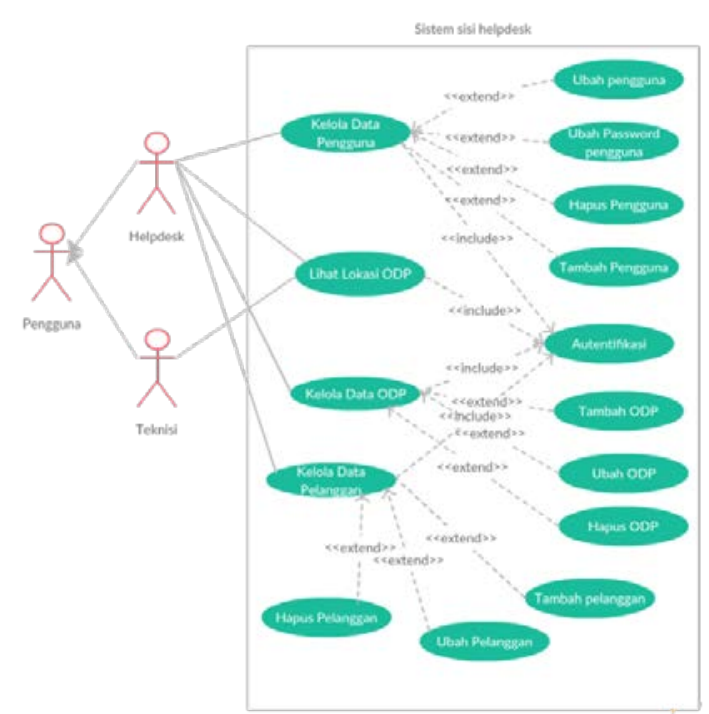

Gambar 4 Usecase diagram sisi Helpdesk

Pada Gambar 4 terdapat 2 aktor yang terlibat yaitu helpdesk dan teknisi yang mewarisi aktor pengguna. Ada 4 fungsionalitas utama untuk sisi helpdesk yaitu :

1. Kelola Data Pengguna. Fungsi Kelola Data Pengguna memiliki opsi tambahan yaitu Tambah Pengguna, Ubah Pengguna, Ubah Password Pengguna dan Hapus Pengguna.

2. Lihat Lokasi ODP. Helpdesk dapat mengetahui letak suatu ODP pada peta.

3. Kelola Data ODP. Fungsi Kelola ODP memiliki opsi tambahan yaitu Tambah ODP, Ubah ODP dan Hapus ODP.

4. Kelola Data Pelanggan.

Fungsi Kelola Data Pelanggan memiliki opsi tambahan berupa Tambah Pelanggan, Ubah Pelanggan, dan Hapus Pelanggan.

Keempat fungsi utama tersebut harus melakukan fungsi Autentifikasi.

Dari sisi teknisi, terdapat dua fungsi utama yang ada pada sistem ini yaitu :

1. Lihat ODP. Teknisi dapat mengetahui letak suatu ODP pada peta.

2. Lihat Data ODP. Teknisi dapat melihat data suatu ODP tertentu, yeknisi dapat melihat daftar pelanggan yang tersambung ke ODP tertentu, Teknisi dapat mengetahui letak suatu ODP dengan nama tertentu

Kedua fungsi tersebut harus melakukan fungsi Autentifikasi.

\subsection{Perancangan Database}


Pada Gambar 5, terdapat tiga entitas yang membangun database sistem informasi geografis pemetaan ODP yaitu MapODP, Pengguna dan Pelanggan. MapODP adalah entitas dari data ODP yang akan disimpan. Entitas Pengguna adalah entitas yang menyimpan data pengguna yang terdiri dari helpdesk dan teknisi. Sedangkan Entitas Pelanggan mencatat pelanggan yang menyambungkan fiber optiknya pada ODP tertentu. Pada sistem yang akan dibangun, database terdiri dari tiga Tabel yaitu Tabel ODP, Tabel Pengguna dan Tabel Pelanggan. Untuk rancanan Tabel database dapat dilihat pada Gambar 6.

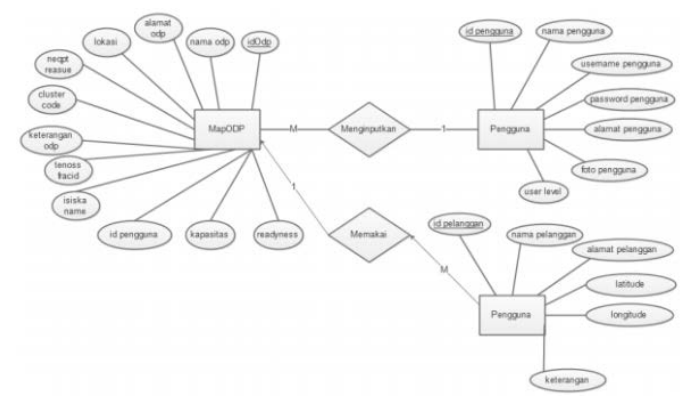

- Gambar 5 Perancangan database

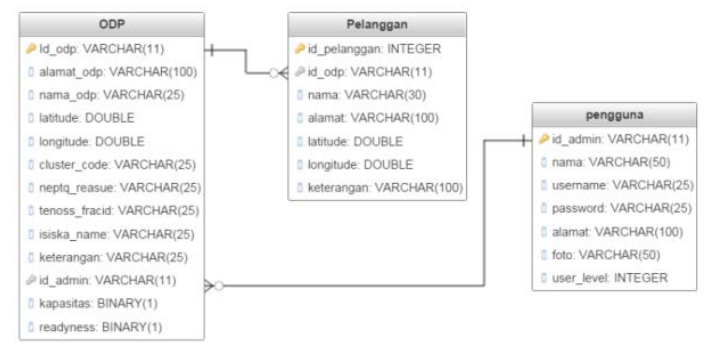

Gambar 6 Rancangan Tabel Database

\section{HASIL DAN PEMBAHASAN}

\subsection{Hasil}

Tahapan-tahapan yang dilakukan dalam memperoleh hasil sistem informasi geografis pemetaan ODP pada PT Telkom Akses Wilayah Bali Selatan berbasis web dan Android adalah sebagai berikut:

1. Implementasi Sistem.

Sistem dari sisi helpdesk akan dibangun menggunakan bahasa pemrograman PHP, Apache Web Server, Database MySQL, dan aplikasi pendukung lainnya. Sistem dari sisi pengguna dibangun menggunakan bahasa pemrograman Java, Java Development Kit (JDK), SDK Android, IDE Android Studio.
2. Pengujian Aplikasi dengan Metode Black Box.

Tahapan pengujian ini dilakukan oleh seorang pengguna (helpdesk dan teknisi), yaitu dengan menjalankan sistem informasi geografis pemetaan ODP berbasis web dan Android dan menggunakan seluruh fitur yang disediakan oleh sistem. Uji coba sistem berbasis web terdiri dari pengujian terhadap proses pengolahan data berupa input, edit dan delete data pada fitur kelola pengguna, kelola ODP dan kelola pelanggan. Sedangkan Uji coba sistem berbasis android terdiri dari pengujian pencarian ODP, informasi ODP detail, dan verifikasi ODP.

\subsection{Pembahasan}

\section{Sistem Berbasis Web}

Terdapat 4 modul yang akan dibahas yaitu login, kelola pengguna, kelola pelanggan dan kelola ODP. Menu login pada Gambar 7 digunakan untuk dapat mengakses halaman dashboard yang bisa dilihat pada Gambar 8 . Form ini berisi username dan password yang harus diisi oleh pengguna untuk dapat masuk ke halaman dashboard.

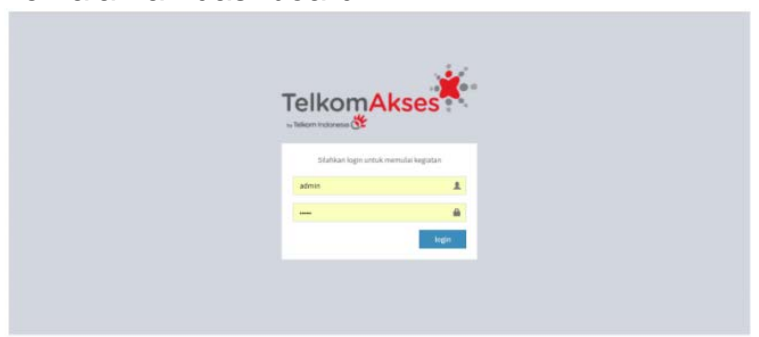
Gambar 7 Tampilan halaman login

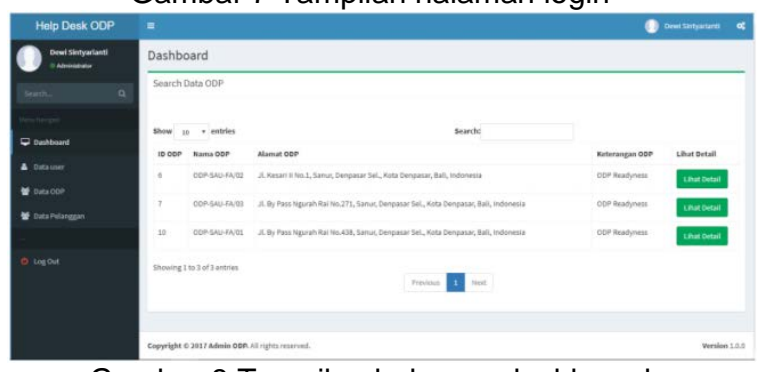

Gambar 8 Tampilan halaman dashboard

Tampilan modul kelola pengguna pada Gambar 9 terdapat list data yang menampilkan data pengguna yang berhak penggunakan sistem. 


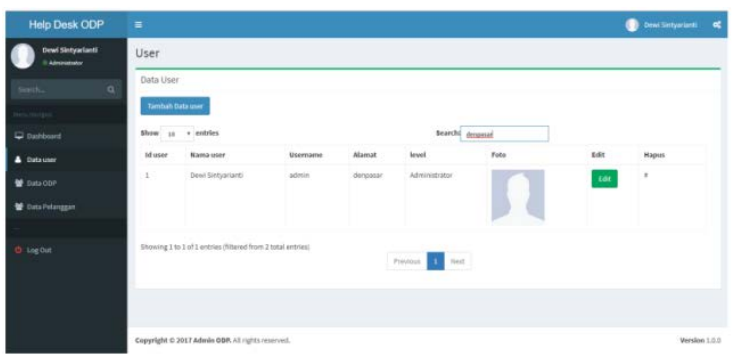

Gambar 9 Tampilan halaman kelola pengguna

Tampilan modul kelola pelanggan pada Gambar 10 terdapat list data yang menampilkan data pelanggan yang dilayani oleh PT. Telkom Akses.

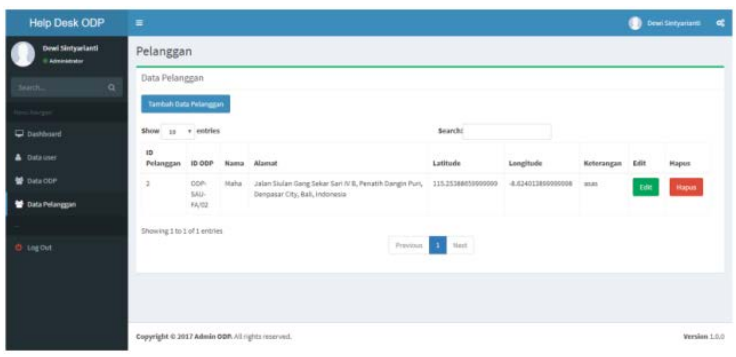

Gambar 10 Tampilan halaman kelola pelanggan

Tampilan modul kelola ODP pada Gambar 11 terdapat list data yang menampilkan data ODP yang dikelola opeh PT Telkom Akses. Pada masing-masing modul helpdesk dapat menambah, mengubah dan menghapus data yang diinginkan dengan meng-klik button tambah, edit, dan hapus.

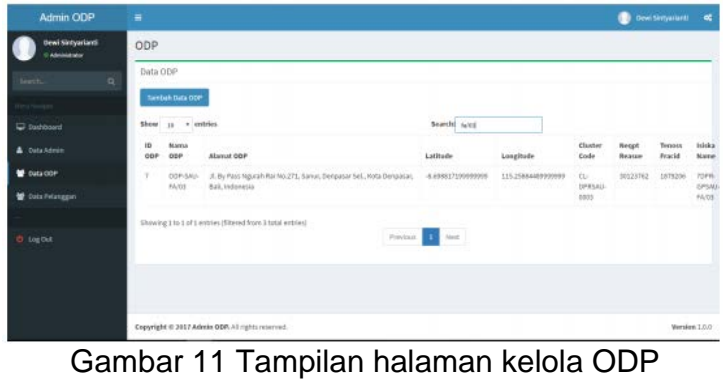

\section{Sistem Berbasis Android}

Tampilan utamanya adalah berupa peta dan marker yang menyatakan lokasi ODP pada peta. Terdapat button untuk memasukan pilihan pencarian ODP berdasarkan nama yang jika di klik akan menampilkan seperti yang ditunjukan oleh Gambar 12. Di atas marker terdapat snippet yang menampilkan nama ODP dan jika di klik akan mengarahkan pengguna ke tamppilan detail ODP. Terdapat juga button refresh untuk mengambil ulang data dan button logout untuk keluar dari sistem.

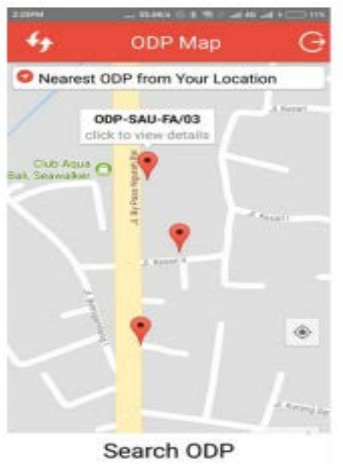

(a)

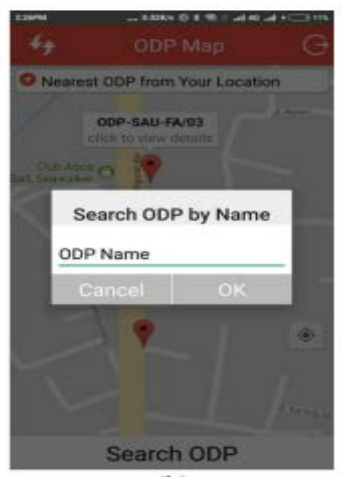

(b)
Gambar 12 Tampilan cari ODP

Gambar 13 adalah tampilan yang memperlihatkan data sebuah ODP. Terdapat beberapa filed yang menampilkan masingmasing data. Terdapat pula radiobutton dan button yang digunakan untuk meng-set status kapasitas dan readyness suatu ODP.

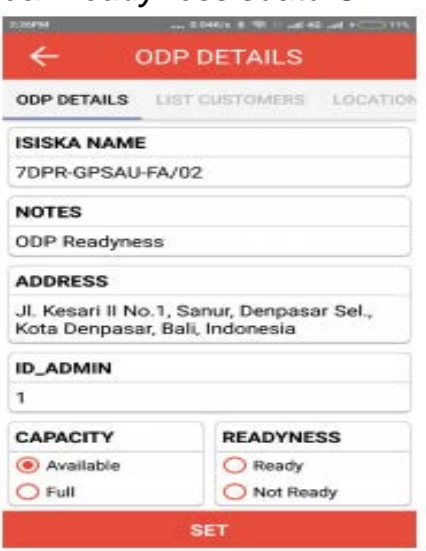

Gambar 13 Tampilan detail ODP

Gambar 14 adalah tampilan yang meperlihatkan daftar pelanggan yang fiber optiknya tersambung dengan ODP tertentu. Pada tampilan tersebut terdapat daftar daftar pelanggan nama ODP tempat pelanggan tersebut tersambung

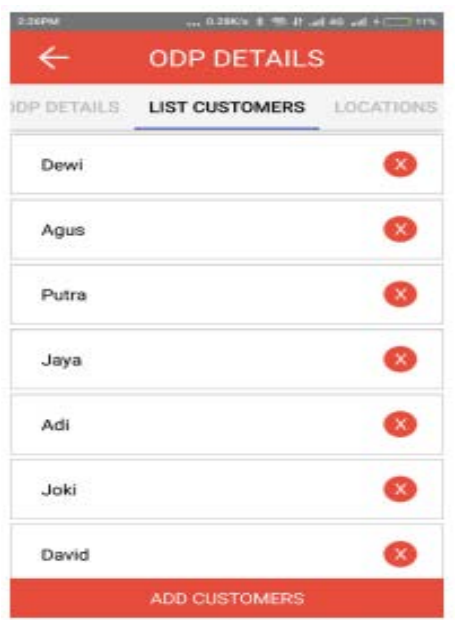


Gambar 14 Tampilan daftar pelanggan

Gambar 15 merupakan tampilan untuk memverifikasi lokasi ODP. Suatu ODP yang dilihat dapat diubah lokasinya dengan cara menempatkan marker di lokasi yang baru pada Google Maps. Setelah lokasi baru ditentukan teknisi dapat menekan button set Lokasi untuk mengkonfirmasi perubahan lokasi ODP

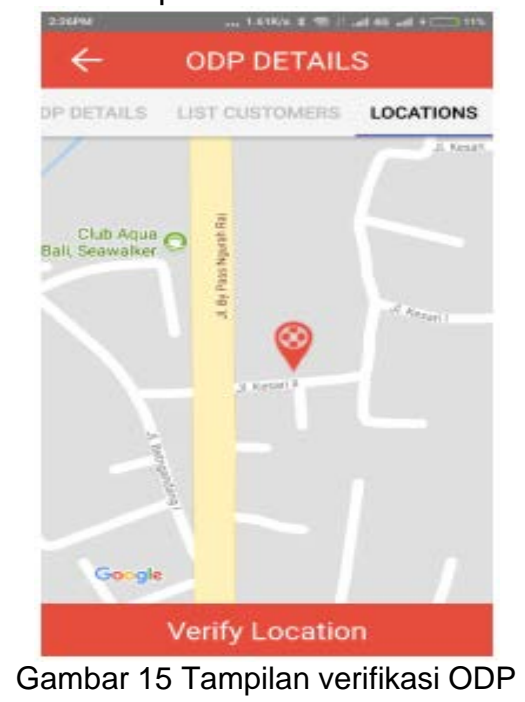

\subsection{Pengujian Sistem}

Pengujian kebutuhan fungsional pada sistem ini menggunakan jenis pengujian sistem dengan teknik black-box. Rencana pengujian ini memetakan setiap kebutuhan fungsional sistem. Pengujian sistem ini akan dilakukan pada dua sisi pengguna yaitu sisi helpdesk dan sisi teknisi.

1. Sisi helpdesk

Pada sisi helpdesk, terdapat empat kebutuhan fungsional sistem yang akan diuji yaitu fungsi :

a. Kelola Data Pengguna. Fungsi Kelola Data Pengguna memiliki opsi tambahan yaitu Tambah Pengguna, Ubah Pengguna, Ubah Password Pengguna dan Hapus Pengguna.

b. Lihat Lokasi ODP. Helpdesk dapat mengetahui letak suatu ODP pada peta.

c. Kelola Data ODP. Fungsi Kelola ODP memiliki opsi tambahan yaitu Tambah ODP, Ubah ODP dan Hapus ODP.

d. Kelola Data Pelanggan. . Fungsi Kelola Data Pelanggan memiliki opsi tambahan berupa Tambah Pelanggan, Ubah Pelanggan, dan Hapus Pelanggan.

2. Sisi teknisi
Pada sisi teknisi terdapat dua kebutuhan fungsional yang harus diuji yaitu :

a. Lihat ODP. Teknisi dapat mengetahui letak suatu ODP pada peta.

b. Lihat Data ODP. Teknisi dapat melihat data suatu ODP tertentu, yeknisi dapat melihat daftar pelanggan yang tersambung ke ODP tertentu, Teknisi dapat mengetahui letak suatu ODP dengan nama tertentu

Sebelum helpdesk dan teknisi dapat mengakses sistem, kedua pengguna tersebut harus melakukan autentifikasi terlebih dahulu. Dari pengujian yang telah dilakukan pada dua sisi pengguna, semua kebutuhan fungsional yang diuji dinyatakan berhasil.

\section{SIMPULAN}

Berdasarkan hasil analisa dan pembahasan diperoleh beberapa simpulan sebagai berikut :

1. Rancang bangun sistem informasi geografis pemetaan Optical Distribution Point (ODP) berbasis web dan Android yang dilengkapi layanan informasi geografis memanfaatkan fitur peta (maps) yang menggunakan layanan Google Maps Api. Google Maps diintegrasikan ke dalam aplikasi berbasis web dan aplikasi berbasis Android untuk memudahkan teknisi untuk mengetahui lokasi ODP.

2. Berdasarkan hasil pengujian sistem informasi geografis pemetaan Optical Distribution Point (ODP) dengan metode Black-box testing, seluruh fungsionalitas dari sistem pemetaan ODP web dan Android yang telah dibangun dapat berjalan dengan baik.

6. Daftar Pustaka

[1] PT Telkom Akses. Tentang Kami: Wilayah Layanan Operasi. (Telkom Akses). http://telkomakses.co.id/tentangkami/wilayah-layanan-operasi/. tanggal 24 April 2017.

[2] Guspa, W. F. Analisis dan perancangan SIstem Informasi Geografis untuk Persebaran Base Transfer Station (BTS) Wilayah Sumbar pada PT. Axiata. https://www.academia.edu/11098023/JUR NAL_Sistem_Informasi_Geografis_untuk_ Persébaran_BTS_wilayah_Sumbar_padā PT_XL_Axiata. Diakses tanggal 26 April 2017.

[3] Labadja, T. A., Siswandari, N. A., \& Puspitorini, O. 2012. Rancang Bangun 
Sistem Informasi Geografis (SIG) untuk pemancar GSM di kota Makassar. Seminar Proyek Akhir Jurusan Teknik Telekomunikasi PENS-ITS.

[4] Horton, J. (2015). Android Programming for Beginners. Birmingham: Packt Publishing Ltd.

[5] Huisman, O., \& A. de By, R. (2009). Principles of Geographic Information Systems. The Netherlands: ITC, Enschede, The Netherlands.

[6] Rumbaugh, J., Jacobson, I., \& Booch, G. 2004. The Unified Modeling Language Reference Manual Second Edition. Boston: Addison-Wesley.

[7] Singh, P. S., Chutia, D., \& Sudhakar, S. (2012). Development of a Web Based GIS Application for Spatial Natural Resources Information System Using Effective Open Source Software and Standards. Journal of Geographic Information System, 261266.

[8] Kreger, H. (2001). Web Services Conceptual Architecture (WSCA 1.0). IBM Software Group.

[9] Nidhra, S., \& Dondeti, J. 2012. Black Box and White Box Testing Techniques -A Literature Review. International Journal of Embedded Systems and Applications (IJESA) Vol.2, 29-50. 